\title{
Rare variants identified in the HNF-4 $\alpha \beta$-cell-specific promoter and alternative exon 1 lack biological significance in maturity onset diabetes of the young and young onset Type II diabetes
}

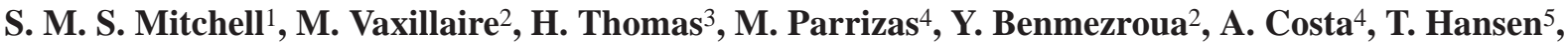 \\ K. R. Owen ${ }^{1}$, T. Tuomi ${ }^{6}$, F. Pirie ${ }^{7}$, G. U. Ryffel ${ }^{3}$, J. Ferrer ${ }^{4}$, P. Froguel ${ }^{8}$, A. T. Hattersley ${ }^{1}$, T. M. Frayling \\ ${ }^{1}$ Department of Diabetes and Vascular Medicine, University of Exeter, Exeter, UK \\ ${ }^{2}$ Department of Human Genetics, Institut Pasteur de Lille, Lille Cedex, France \\ ${ }^{3}$ Institute for Cell Biology, Essen University Clinic, Essen, Germany \\ ${ }^{4}$ Endocrinology and Diabetes Unit, University Hospital Clinic, Institut d'Investigacions Biomèdiques August Pi i Sunyer, Barcelona, \\ Spain \\ 5 Steno Diabetes Center, Niels Steensens VEJ2, Gentofte, Denmark \\ ${ }^{6}$ Department of Medicine, Helsinki University Central Hospital, Helsinki, Finland \\ ${ }^{7}$ Cooper Medical Centre, Entabeni Hospital, Durban, South Africa \\ ${ }^{8}$ Queen Mary and Westfield College, University of London, and Barts and The London Genome Centre, London, UK
}

\begin{abstract}
Aims/hypothesis. The recently identified alternative promoter (P2) of $H N F-4 \alpha$ is the major $H N F-4 \alpha$ transcription start site in pancreatic beta cells. The significance of the $\mathrm{P} 2$ promoter was shown by the identification of a mutation in the IPF-1 binding site of the alternative promoter which cosegregated with diabetes in a large MODY family. The role of the P2 promoter and the associated alternative exon 1 in both MODY and polygenic Type II (non-insulin-dependent) diabetes mellitus is not known. Linkage to this region in studies of Type II diabetes makes the P2 region a strong candidate for a role in Type II diabetes susceptibility.

Methods. To assess the role of the $\mathrm{P} 2$ region we screened MODY, young-onset Type II diabetic subjects, and probands from Type II diabetes families linked to chromosome 20 for variants of the P2 promoter and associated exon of $H N F-4 \alpha$.
\end{abstract}

Results. Two variants were found that were not present in the control subjects. The $-79 \mathrm{C} / \mathrm{T}$ substitution was present in a MODY family but did not perfectly cosegregate with diabetes. A $-276 \mathrm{G} / \mathrm{T}$ substitution was identified in two UK young-onset diabetes probands but did not co-segregate with diabetes. Reporter gene studies did not indicate changes in transcriptional activity caused by either the $-79 \mathrm{C} / \mathrm{T}$ or $-276 \mathrm{G} / \mathrm{T}$ single nucleotide substitutions.

Conclusion/interpretation. We found no evidence to suggest that variation in the $\mathrm{P} 2$ proximal promoter region and associated alternative exon 1 of $H N F-4 \alpha$ contribute to young onset Type II diabetes susceptibility in Northern Europeans. [Diabetologia (2002) 45:1344-1348]

Keywords: $H N F 4-\alpha, H N F-1 \alpha, H N F-1 \beta$, IPF-1, maturity onset diabetes of the young, Type II diabetes mellitus, $\mathrm{P} 2$ promoter.
Mutations in the transcription factor genes hepatic nuclear factor $(H N F)-1 \alpha, H N F-1 \beta$ and $H N F-4 \alpha$ and in-

Received: 18 March 2002 / Revised: 21 May 2002

Published online: 19 July 2002

C) Springer-Verlag 2002

Corresponding author: T. M. Frayling, $\mathrm{PhD}$, Department of Diabetes and Vascular Medicine, University of Exeter, Barrack Road, Exeter, UK, EX2 5AX, E-mail: t.m.frayling@exeter.ac.uk sulin promoter factor $1(I P F-1)$ cause the majority of cases of MODY [1]. The mechanism by which $H N F$ $1 \alpha, H N F-1 \beta, H N F-4 \alpha, I P F-1$ and other genes interact to result in normal beta-cell function is uncertain.

Recently it has been recognised that in the beta cell the predominant isomer of $H N F-4 \alpha$ is $H N F-4 \alpha 7$ which utilises a far upstream promoter of $H N F-4 \alpha$, $\mathrm{P} 2$, with an alternative exon 1 that in humans is $45 \mathrm{~kb}$ $5^{\prime}$ to the previously identified $\mathrm{P} 1$ promoter $[2,3,4]$. The P2 promoter contains functional binding sites for 
$H N F-1 \alpha, H N F-1 \beta$ and $I P F-1[3,4]$. This suggests that $H N F-1 \alpha, H N F-1 \beta$ and $I P F-1$ could regulate $H N F-4 \alpha$ through the $\mathrm{P} 2$ promoter in the pancreas, in contrast to the situation in the liver where $H N F-4 \alpha$ regulates $H N F-1 \alpha$. Consistent with this, $H N F-1 \alpha$ was recently found to be essential for P2 promoter activity and nucleosomal histone hyperacetylation in mice [4]. Furthermore, we identified a large MODY family with a $-146 T / C$ nucleotide substitution in the IPF- $I$ binding site of the $\mathrm{P} 2$ promoter, which cosegregated with diabetes (LOD3.25) [3]. This mutation was shown to reduce transcriptional activity in a beta-cell line by reducing the binding of $I P F-1$ [3].

$H N F-4 \alpha$ is located on chromosome 20q12-q13.1. Several groups have reported linkage of Type II (noninsulin-dependent) diabetes mellitus to this region. These include studies of US Caucasians, Finnish and French Type II diabetes families [5, 6, 7, 8, 9, 10, 11]. As a strong candidate gene, $H N F-4 \alpha$ exons and promoter P1 have been screened in a number of these studies but not the $\mathrm{P} 2$ promoter. Common variants in the P1 promoter and the downstream exons did not explain the observed linkages to this region $[8,11]$.

The role of genetic variation in the $\mathrm{P} 2$ promoter and the associated exon in non-MODY Type II diabetes has not been studied. Given the evidence for linkage to the genomic region of $H N F-4 \alpha$ and its crucial regulatory role in the pancreas it represents a strong candidate for a role in Type II diabetes susceptibility. Although we identified one co-segregating mutation in one of seven MODY families [3], the role of the P2 promoter and associated exon has not been evaluated in further MODY families in whom a mutation has not been found. We therefore screened Northern European subjects with Type II diabetes or MODY for variation in the $\mathrm{P} 2$ promoter and associated exon of $H N F-4 \alpha$.

\section{Subjects and methods}

Subjects. The first group we studied comprised: 25 MODY probands that were previously found to have no mutations in the five known MODY genes [12, 13, 14]: one South African of Indian origin, one Spaniard, two Italians, two Danes, two Swedes, four Finns and 13 French probands meeting MODY criteria (autosomal dominant inheritance of Type II diabetes with at least one family member diagnosed before 25 years of age) (Table 1). Of these 25 families, seven had LOD scores at the $H N F 4 \alpha$ locus of less than -2.0 . All other families were either too small for linkage analyses $(n=8)$ or could not be excluded at LOD less than -2.0 (LODs ranged from -1.92 to +1.01 ). In one family we identified a mutation in the $H N F 4 \alpha$ P1 promoter but given this promoter does not act in the beta cell the proband from this family was included.

The second group included: Young onset (non-MODY) Type II diabetic subjects: 48 white diabetic subjects from the United Kingdom of British or Irish origin, who were GAD negative with at least one Type II diabetic first degree relative, and 38 French young onset Type II diabetic subjects, in whom linkage to chromosomal region $20 \mathrm{q} 13$ had been found [7] (Table 1).

The third group included: 48 white non-diabetic subjects from the United Kingdom $\left(\mathrm{HbA}_{1 \mathrm{C}}<6.0 \%\right)$ (Table 1). All subjects gave informed consent and the investigations were carried out in accordance with the Declaration of Helsinki.

Sequencing. We PCR-amplified and sequenced the P2 promoter, encompassing the HNF-1 and IPF-1 binding sites, and the associated alternative exon 1 using genomic DNA [3]. The following overlapping primer pairs were designed and used separately by the collaborating laboratories:

Forward 5'-CCAGGTTGGACTCTCACCTCTC-3' and Reverse 5'-GTGTCCCATGGCCTCCCAAAG-3' amplifying bases -383 to 116 of the P2 promoter and exon (42786617 to 42787115 from the p-terminal of chromosome 20); or Forward 5'-TGACACACCCATAGTTTGGAG-3' and Reverse 5'-ATGGCCTCCCAAAGCTGAC-3' amplifying bases -418 to 109 of the P2 promoter and exon (42786582 to 42787108 (UCSC Human Genome Project Working Draft, 22 December 2001 assembly (hg10) http://genome.cse.ucsc.edu/)).

Cell lines, transfections and reporter gene assays. Luciferase reporter gene constructs were generated by introducing PCR fragments containing the appropriate $H N F-4 \alpha \mathrm{P} 2$ promoter sequence into vectors pGL2-Basic (-79C/T variant) or pGL3-BasicII (Promega) (-276G/T variant). For the $-79 \mathrm{C} / \mathrm{T}$ constructs, bases -54 to -371 of the P2 promoter were PCR amplified with forward primer 5'-TTTGAGCTCACCTCTCCAGCCCCTTCT-3' and two different reverse primers: 5'-GGACTCGAGCACAGCAGCAGCACAGCCACCAGGAACCCG-3' for the $\mathrm{T}$ variant and 5'-GGACTCGAGCACAGCAGCAG-3' for

Table 1. Clinical characteristics of the subjects examined according to diabetes status

\begin{tabular}{lllll}
\hline $\begin{array}{l}\text { Clinical } \\
\text { characteristic }\end{array}$ & MODY X & $\begin{array}{l}\text { UK young onset diabetic } \\
\text { subjects (non-MODY) }\end{array}$ & $\begin{array}{l}\text { French young onset diabetic } \\
\text { subjects (non-MODY) }\end{array}$ & $\begin{array}{l}\text { UK non-diabetic } \\
\text { subjects }\end{array}$ \\
\hline$N$ & 25 & 48 & 38 & 48 \\
Male/female & $11 / 14$ & $30 / 18$ & $21 / 17$ & $26 / 22$ \\
Age (years) & $16(12-27)$ & $36.0(32.0-39.5)$ & $36.0(28.5-39.8)$ & $70(62-74)$ \\
BMI & $24.7(21.8-27.7)$ & $29.6(28.0-33.5)$ & $26.1(23.4-29.3)$ & - \\
Treatment with diet (\%) & 9.5 & 35.4 & 63.2 & - \\
Treatment with OHA (\%) & 14.3 & 47.9 & 26.3 & - \\
Treatment with insulin (\%) & 76.2 & 16.7 & 10.5 & \\
\hline
\end{tabular}

a Age at diagnosis for Diabetic subjects, age at study for non-diabetic subjects

Data are $n, \%$ or medians (interquartile range) 
Table 2. Frequency of the $H N F 4 \alpha \mathrm{P} 2$ variants identified in the four study groups

\begin{tabular}{lllll}
\hline Mutation & Allele frequency & & \\
\cline { 2 - 5 } & MODY X & $\begin{array}{l}\text { UK young onset diabetic } \\
\text { subjects (non-MODY) }\end{array}$ & $\begin{array}{l}\text { French young onset diabetic } \\
\text { subjects (non-MODY) }\end{array}$ & $\begin{array}{l}\text { UK non-diabetic } \\
\text { subjects }\end{array}$ \\
\hline$-79 \mathrm{C} / \mathrm{T}$ & C: $0.98 \mathrm{~T}: 0.02$ & C: $1.00 \mathrm{~T}: 0.00$ & C: $1.00 \mathrm{~T}: 0.00$ & C: $1.00 \mathrm{~T}: 0.00$ \\
$-276 \mathrm{G} / \mathrm{T}$ & G: $1.00 \mathrm{~T}: 0.00$ & G: $0.98 \mathrm{~T}: 0.02$ & G: $1.00 \mathrm{~T}: 0.00$ & G: $1.00 \mathrm{~T}: 0.00$ \\
\hline
\end{tabular}

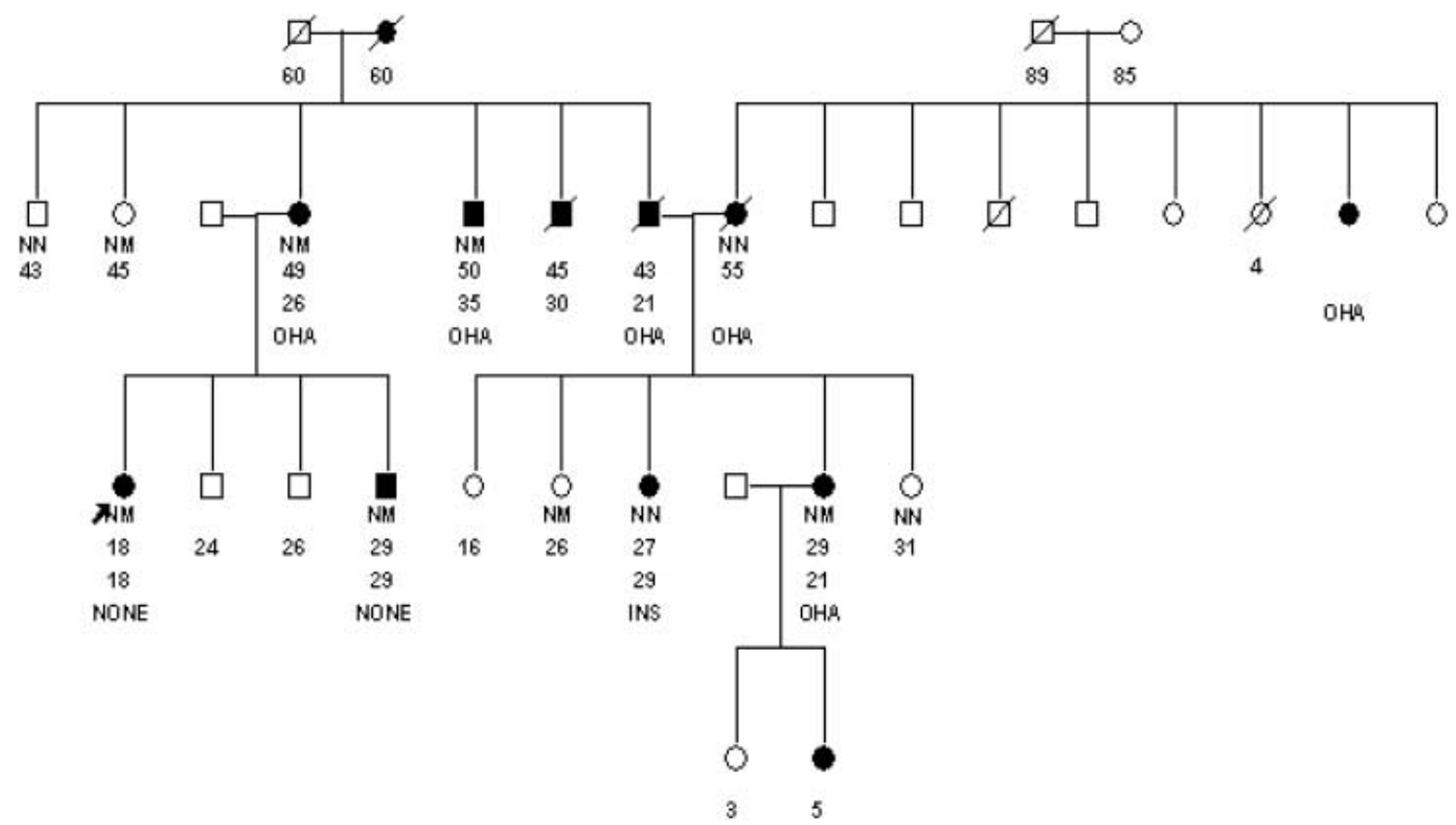

Fig. 1. Pedigree of MODYX family showing pattern of inheritance of the $\mathrm{C} / \mathrm{T}$ nucleotide substitution at -79 . Solid symbols represent affected and open symbols unaffected individuals. Individual mutation status is given: $\mathrm{N}=$ normal, $\mathrm{M}=\mathrm{C} / \mathrm{T}$ mutation. For affected subjects: age at testing followed by age at diagnosis followed by treatment regime (OHA oral hypoglycaemic agents, INS = insulin) are given. For unaffected subjects age at testing is given. The proband is indicated by an arrow

the $\mathrm{C}$ variant. For the $-276 \mathrm{G} / \mathrm{T}$ variant, constructs were made containing nucleotides -1 to -346 (P2/-346) or nucleotides -1 to -2200 (P2/-2200) of the $\mathrm{P} 2$ promoter to exclude the possibility that the mutation influences more distal unidentified regulatory elements. PCR was carried out with forward primers 5'-CCGCTCGAGCGGCCCTGTCCTCAAATTG-3' for P2/346 and 5'-CCGCTCGAGGGAAGGCAATGTGAGA-3' for $\mathrm{P} 2 /-2200$ and the reverse primer 5'-CCCAAGCTTGGGCCAAGCCCACCCAGC-3'.

To increase the possibility of testing the mutation in a representative cellular context, two cell lines were used to test the functional effect of each mutation. INS-1 and FT0-2B cells [15] were cultured and transfected [3]. Min6 and $\mathrm{CaCo} 2$ cells were cultured in DMEM with $50 \mathrm{mmol} / \mathrm{l} \beta$-mercaptoethanol and $15 \%$ foetal calf serum. Transfections of MIN6 and CaCo2 cells were done using $0.4 \mu \mathrm{g}$ of $H N F-4 \alpha$-P2 luciferase reporter gene constructs using Effectene (Qiagen) at a 1:10 ratio to DNA.

\section{Results}

We identified one variant in the MODYX subjects: a $-79 \mathrm{C} / \mathrm{T}$ nucleotide substitution (Table 2). The variant did not co-segregate completely with diabetes but was present in five of the seven diabetic family members screened and was also present in two of the four nondiabetic family members screened (Fig. 1). The -79 $\mathrm{C} / \mathrm{T}$ variant was not seen in any of the non-diabetic subjects from the UK.

The $-79 \mathrm{C} / \mathrm{T}$ variant is contained within the $5^{\prime}$ untranslated region of $H N F-4 \alpha$ transcripts originating from the P2 promoter, and is conserved in mice and humans. To analyse its effect on transcriptional activity, we mutated this site in a luciferase reporter gene construct containing the P2 promoter sequence. Transient transfections in mouse Min6 beta-cells and human colon-derived $\mathrm{CaCo} 2$ cells failed to show differences in transcriptional activity between the constructs containing $\mathrm{C}$ or $\mathrm{T}$ at position -79 (Fig. 2).

In 2 of 48 UK young onset (non-MODY) Type II diabetic subjects we identified a -276 G/T nucleotide substitution (Table 2). However, in each case it was inherited from an unaffected parent and was not present in an affected first degree relative. The $-276 \mathrm{G} / \mathrm{T}$ variant was not present in either the 38 French young 
Variant $-79 \mathrm{C} \rightarrow \mathrm{T}$
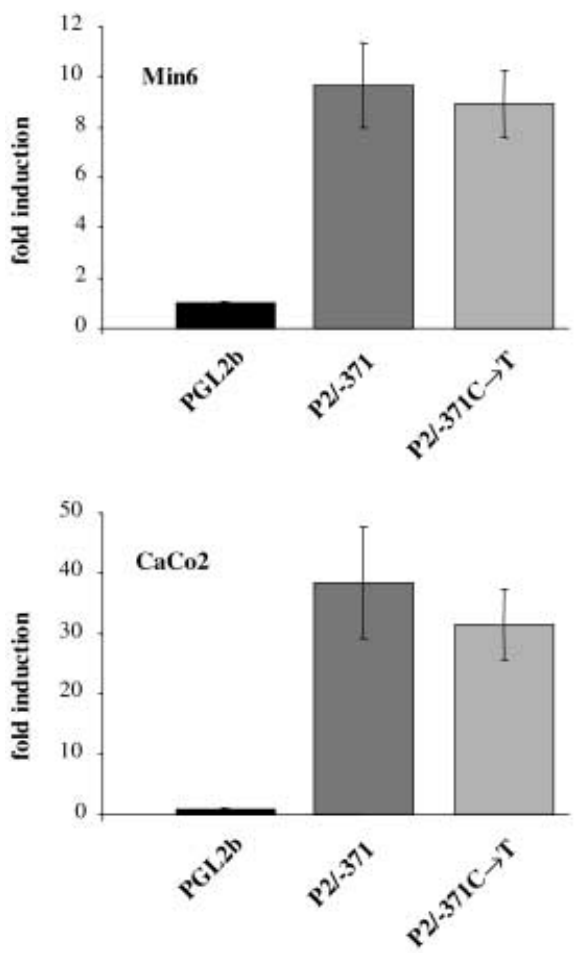

Fig. 2. Luciferase reporter gene assays of transiently transfected Min6 and $\mathrm{CaCo} 2$ cells using $\mathrm{P} 2$ promoter constructs containing either the $\mathrm{C}(\mathrm{P} 2 /-371)$ or the $\mathrm{T}(\mathrm{P} 2 /-371 \mathrm{C} \rightarrow \mathrm{T})$ variants at position -79 where -371 indicates the $5^{\prime}$ extent of the promoter used in the construct relative to the translation start site. Fold induction refers to the activity of the pGL2-Basic vector. Standard error bars were calculated from three different experiments, each representing duplicate calculations of two independent clones for each construct

onset (non-MODY) Type II diabetic subjects, or in the 48 UK nondiabetic subjects. The previously reported $-146 \mathrm{~T} / \mathrm{C}$ substitution was not present in any of the subjects studied.

The $-276 \mathrm{~T}$ variant occurs in a potential metal responsive element (TGCRCNC) in the opposite strand [16]. To assess whether variation at this site affects transcriptional activity, we undertook luciferase reporter gene assays of transiently transfected insulinoma (INS-1) and hepatoma (FT0-2B) cell lines. We used constructs containing the $-276 \mathrm{G}$ or $\mathrm{T}$ variant in fragments of the P2 promoter containing bases -1 to -346 or -1 to -2200 in front of the luciferase gene. No difference in fold activity was seen between the constructs containing the $\mathrm{G}$ variant and those containing the $\mathrm{T}$ variant in either of the cell lines (Fig. 3).

\section{Discussion}

Our results do not support the hypothesis that variation in the far upstream P2 promoter is an important
Polymorphism -276G $\rightarrow$ T
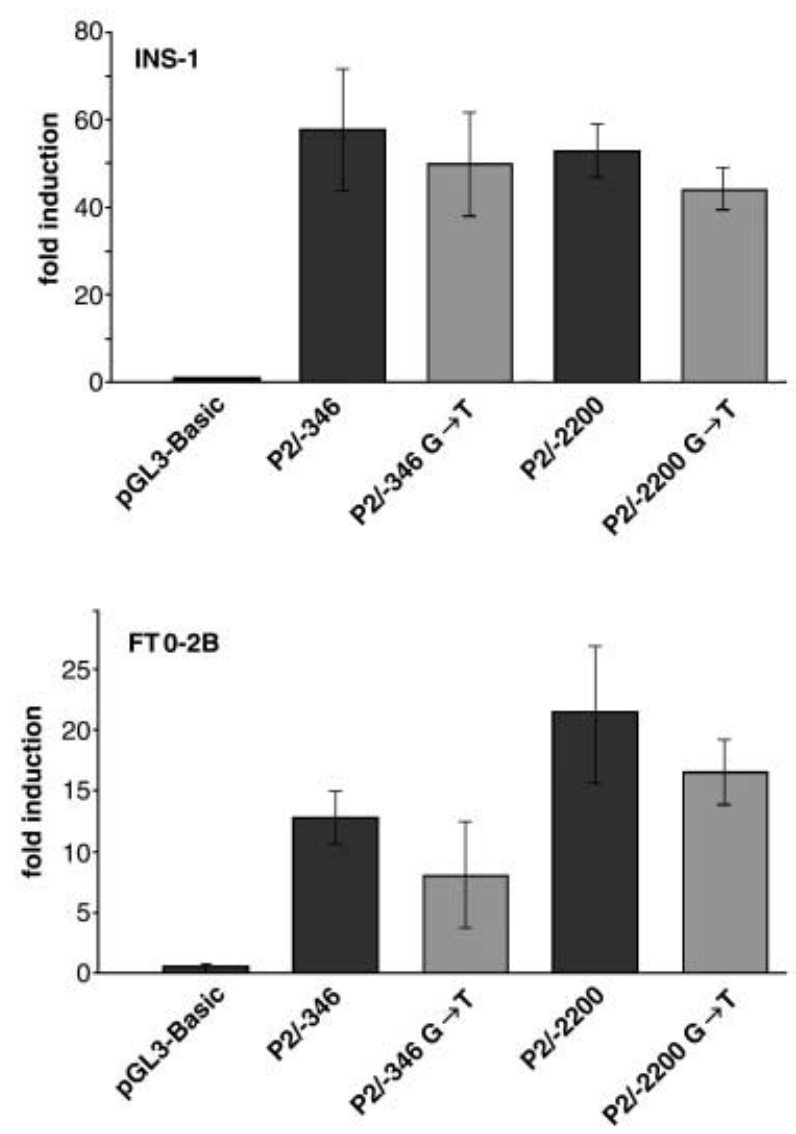

Fig. 3. Luciferase reporter gene assays of transiently transfected INS-1 and FT0-2B cells using the following reporter gene constructs of the $\mathrm{P} 2$ promoter sequence of $H N F-4 \alpha$ in front of the luciferase gene: $\mathrm{P} 2 /-346, \mathrm{P} 2 /-2200$ as well as $\mathrm{P} 2 /-346 \mathrm{G} \rightarrow \mathrm{T}$ and $\mathrm{P} 2 /-2200 \mathrm{G} \rightarrow \mathrm{T}$ containing the polymorphism $-276 \mathrm{G} \rightarrow \mathrm{T}$ (where -346 or -2200 indicates the $5^{\prime}$ extent of the promoter used in the construct relative to the translation start site). Fold induction refers to the activity of the pGL3-Basic vector. The error bars indicate standard deviations of six calculations

cause of MODY or young onset Type II diabetes even in families showing linkage to this region. It remains possible that variation in the $\mathrm{P} 2$ promoter and associated exon is a minor contributor to Type II diabetes susceptibility, although given their low frequency, variants will only contribute to a small proportion of the linkage results. However, the role of the P2 promoter in the aetiology of Type II diabetes should be investigated in cohorts of late-onset Type II diabetes subjects. Although we have excluded up to $418 \mathrm{bp}$ of the $\mathrm{P} 2$ promoter region and the associated exon from a role in our cohorts it remains possible that variation in distant unidentified transcriptional control elements of this promoter could be important in Type II diabetes susceptibility.

In conclusion, variation in the $H N F-4 \alpha \mathrm{P} 2$ promoter and the corresponding exon are not a common cause of MODY or early-onset Type II diabetes in- 
cluding those from families linked to chromosome 20. It is not likely that variation in the $\mathrm{P} 2$ region of $H N F$ $4 \alpha$ accounts for the previously identified linkage between this region and Type II diabetes although it cannot be excluded from a role in late onset Type II diabetes.

Acknowledgements. S.M.S. Mitchell is a Diabetes UK award $\mathrm{PhD}$ student. Dr. T. Frayling is a career scientist of the South and West National Health Service Research Directorate. Dr. A. Costa was supported by a research fellowship from Institut d'Investigacions Biomedicas August Pi i Sunyer (IDIBAPS). Dr. H. Thomas and Professor G.U. Ryffel were supported by the Deutsche Forschungsgemeinschaft (Th799/1-1). Dr. J. Ferrer is funded by the Spanish Ministry of Science and Technology (SAF2001-2457) and the European Union. We are indebted to Dr. M.A. Maestro for cloning the $\mathrm{P} 2 /-371 \mathrm{C} \rightarrow \mathrm{T}$ plasmids and to Dr. Lipsanen-Nyman for providing a MODYX family. We also gratefully acknowledge EU funding to the Genomic Integrated Force for Type II Diabetes (GIFT) consortium.

\section{References}

1. Hattersley AT (1998) Maturity-onset diabetes of the young: clinical heterogeneity explained by genetic heterogeneity. Diabet Med 15: 15-24

2. Nakhei H, Lingott A, Lemm I, Ryffel GU (1998) An alternative splice variant of the tissue specific transcription factor $\mathrm{HNF} 4 \alpha$ predominates in undifferentiated murine cell types. Nucleic Acids Res 26: 497-504

3. Thomas H, Jaschkowitz K, Bulman M et al. (2001) A distant upstream promoter of the HNF-4alpha gene connects the transcription factors involved in maturity-onset diabetes of the young. Hum Mol Genet 10: 2089-2097

4. Boj SF, Parrizas M, Maestro MA, Ferrer J (2001) A transcription factor regulatory circuit in differentiated pancreatic cells. Proc Natl Acad Sci USA 98: 14481-14486

5. Bowden WD, Sale M, Howard TD et al. (1997) Linkage of genetic markers on human chromosomes 20 and 12 to NIDDM in Caucasian sib pairs with a history of diabetic nephropathy. Diabetes 46: 882-886
6. Ji L, Malecki M, Warram JH, Yang Y, Rich SS, Krolewski AS (1997) New susceptibility locus for NIDDM is localized to human chromosome 20q. Diabetes 46: 876-881

7. Zouali H, Hani EH, Philippi A et al. (1997) A susceptibility locus for early-onset non-insulin dependent (type 2) diabetes mellitus maps to chromosome 20q, proximal to the phosphoenolpyruvate carboxykinase gene. Hum Mol Genet 6: $1401-1408$

8. Ghosh S, Watanabe RM, Hauser ER et al. (1999) Type II diabetes: evidence for linkage on chromosome 20 in 716 Finnish affected sib pairs. Proc Nat Acad Sci USA 96: 2198-2203

9. Klupa T, Malecki MT, Pezzolesi M et al. (2000) Further evidence for a susceptibility Locus for type 2 diabetes on chromosome 20q13.1-q13.2. Diabetes 49: 2212-2216

10. Permutt MA, Wasson JC, Suarez BK et al. (2001) A genome scan for Type II diabetes susceptibility loci in a genetically isolated population. Diabetes 50: 681-685

11. Malecki MT, Antonellis A, Casey P et al. (1998) Exclusion of the Hepatocyte Nuclear Factor $4 \alpha$ as a candidate gene for late-onset NIDDM linked with chromosome 20q. Diabetes 47: 970-972

12. Beards F, Frayling T, Bulman M et al. (1998) Mutations in hepatocyte nuclear factor 1 beta are not a common cause of maturity-onset diabetes of the young in the UK. Diabetes 47: 1152-1154

13. Chevre JC, Hani EH, Boutin P et al. (1998) Mutation screening in 18 Caucasian families suggest the existence of other MODY genes. Diabetologia 41: 1017-1023

14. Lehto M, Wipemo C, Ivarsson S-A et al. (1999) High frequency of mutations in MODY and mitochondrial genes in Scandinavian patients with familial early-onset diabetes. Diabetologia 42: 1131-1137

15. Asfari M, Janjic D, Meda P, Li G, Halban PA, Wollheim CB (1992) Establishment of 2-mercaptoethanol-dependent differentiated insulin-secretingcell lines. Endocrinology 130: $167-178$

16. Radtke F, Heuchel R, Georgiev O et al. (1993) Cloned transcription factor MTF-1 activates the mouse metallothionein Ipromoter. EMBO J 12: 1355-1362 